Nikola Vujnović $₫$

Dean Vidak

Fran Jakšić

Željko Kedmenec

Damir Dović

Ivan Horvat

https://doi.org/10.21278/TOF.45Si1007021

ISSN 1333-1124

eISSN 1849-1391

\title{
DIFFERENCES IN CALCULATIONS OF ANNUAL HEATING AND COOLING ENERGY NEED CARRIED OUT BY MODIFIED SIMPLE HOURLY METHOD AND DYNAMIC SIMULATIONS
}

\begin{abstract}
Summary
This paper presents differences in calculations of annual heating and cooling energy need performed by numerical dynamic simulations software IDA ICE and those carried out by the modification of simple hourly method from EN ISO 13790 EN ISO 13790, widely used for determining building energy need. A simple model of a nearly-zero energy building was created and all heat gains and set-points that could lead to a mismatch in initial or boundary conditions were analysed. The impact of those on the annual heating and cooling energy need was examined by adding and/or removing every single one of them. Boundary conditions in numerical dynamic simulations were set up to match those in simple hourly method. Such an approach enables evaluation of differences in results and definition of their origin. The comparison of results has shown that in most cases, annual energy need for heating and cooling calculated using numerical dynamic simulations software differs from that calculated using EN ISO 13790. Among the others, more detailed heat accumulation model of heat gains in building's envelope in IDA ICE software was marked as the main reason. Fact that solar heat gains seem to be underestimated by EN ISO 13790 and differences in heat transfer towards ground contribute to the differences in results as well.
\end{abstract}

Key words: $\quad$ building energy need, simple hourly method, dynamic simulation, heat energy accumulation, heat gains

\section{Introduction}

Main goal of Directive on energy performance of buildings (EPBD), 2010/31/EU is to reduce the primary energy consumption in buildings, which is assumed to be $40 \%$ of total energy consumption in EU. In order to do so, a procedure for calculation of the energy need for existing and new buildings is provided with a number of CEN standards. Therefore, application of common calculation procedures for building energy need is also one of the goals of Directive on energy performance of buildings (EPBD), 2010/31/EU. Since the procedures that are currently provided with CEN standards differ by time step or required 
amount of input data, it is important to compare various calculation procedures and understand the differences in results obtained using those. In [2], which is one of the abovementioned standards, three types of methods are provided: a fully prescribed monthly method, a fully prescribed simple hourly method and guidelines for performing calculations by using dynamic simulations software. In Croatia, the monthly method is considered insufficiently accurate due to the too large time step for precise determination of need for mechanical ventilation of complex systems. Therefore, the simple hourly method has become the most used for performing building energy need calculations, especially due to its reduced complexity when compared to the use of dynamic simulations. The validation of the method is given by Michalak in [3], with EnergyPlus detailed simulation method as reference. Lots of authors have worked on this theme. The building thermal model by Mendes et al. [4] enables calculations of the heat transfer through building envelope in arbitrary time interval, but is suspected to be insufficiently accurate due to many simplifications, as well as method by Qin et al. [5]. The reason is neglection of heat accumulation in walls. The detailed building model is similar to that developed by De Rosa et al. [6], where complex mathematical operations are used to determine heating or cooling energy need. In [7], by the means of similar approach, some limitations of heat transfer through walls simulation are underlined by $\mathrm{Lu}$ et al. In [8], Van der Veken et al. have stated that calculations based on methods from [2] result in lower annual energy need for cooling. The same conclusion was made by Evangelisti et al. in [9], due to use of simple coefficients for calculation of stationary heat transfer and heat accumulation in [2]. Also, Delač [10] states that solar heat gains are underestimated by [2], especially in cases with avg. day as an input.

The existing hourly method incorporated in the Croatian national Algorithm for calculation of the annual heating and cooling energy need according to EN ISO 13790 (used for energy certification of buildings) differs from the original simple hourly method in [2] because it includes heat transfer rate towards the ground, which the original does not include. In original, heat transfer coefficient towards ground is a part of total heat transmission transfer coefficient. This approach proved to be insufficiently accurate when calculating energy need for cooling. In MGIPU Energy certificator [11] (hereafter, EC, official national software used for determining primary energy) simple hourly method from [11] is not applied as a hour-byhour calculation procedure, but as a simplified method with an input of average day of a characteristic month (hereafter, avg. day). The procedure will be described in more detail. In this paper a comparison between such a method, imitation of it in the software for dynamic simulations (IDA ICE), and a dynamic hour-by-hour simulation is given (IDA ICE).

\section{Methods}

2.1 Simple hourly method and its implementation into Croatian national Algorithm for calculation of the annual heating and cooling energy need according to EN ISO 13790

Simple hourly calculation procedure is a simplification of a dynamic simulation. It was introduced to take into account hourly variations in weather, operation schedules, controls etc. and their real-time interactions with energy need for heating and cooling. At the same time, it requires the same amount of input data as the monthly method from [2] (e.g. heat transmission is calculated using heat transfer coefficients - the same as in the monthly method).

\subsubsection{R1C model}

Simple hourly method is based on an equivalent resistances and one capacitance (5R1C) model of a heated or cooled zone. The model is described in [2] and the analogy between the thermal and electrical resistances and capacities is based on the physical and mathematical resemblance of electric current and heat flux. The model is graphically presented in Figure 1. 


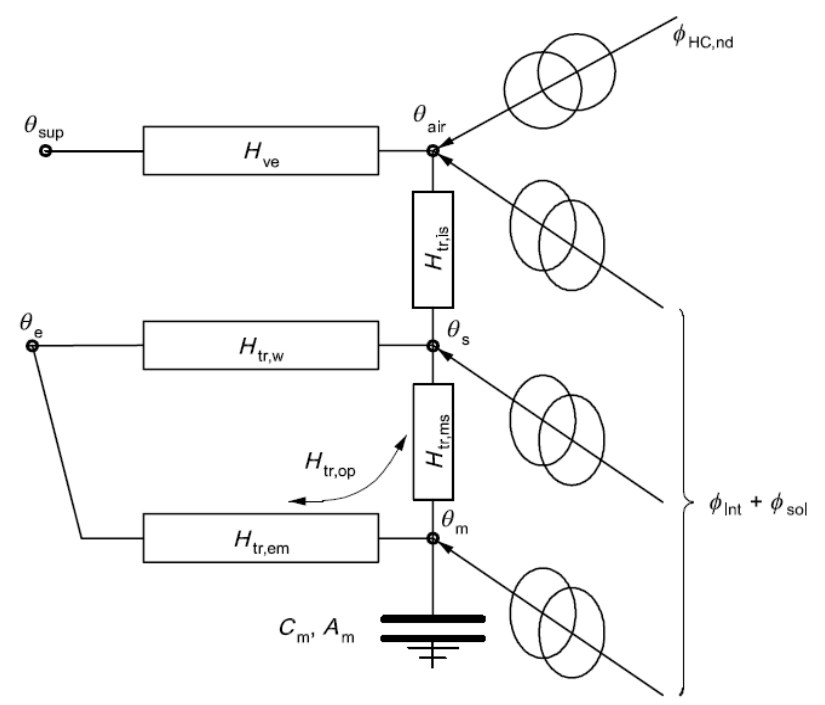

Fig. 1 Illustration of the 5R1C model [1]

There are two nodes outside the building: the node representing the supply air temperature $\left(\vartheta_{\text {sup }}\right)$ and the external air temperature node $\left(\vartheta_{e}\right)$. In [11] energy need for heating or cooling $\left(\phi_{H C, n d}\right)$ should obtain energy requirements of HVAC and room system mutually, so the supply air temperature $\left(\vartheta_{\text {sup }}\right)$ is equal to the external air temperature $\left(\vartheta_{e}\right)$, as described in [9].

There are three nodes inside the external envelope of the building (zone). Internal air temperature node $\left(\vartheta_{\text {air }}\right)$ - the temperature of the air in the centre of the zone, node representing internal surface $\left(\vartheta_{s}\right)$ and there is also the node $\left(\vartheta_{m}\right)$ connected to the the thermal mass of walls of the calculated zone.

The heating or cooling power $\left(\phi_{H / C, n d}\right)$ is defined as the heat flow supplied to or extracted from the internal air node $\left(\vartheta_{\text {air }}\right)$ in the amount needed to maintain the given set-point of indoor air temperature: $\vartheta_{\text {int, } H, \text { set }}$ for heating or $\vartheta_{\text {int }, C, \text { set }}$ for cooling.

The heat transfer coefficient by ventilation $\left(H_{v e}\right)$ is connected directly to $\vartheta_{\text {sup }}$ and $\vartheta_{\text {air }}$. $H_{t r, w}$ is the transmission heat transfer coefficient for elements taken as having no thermal mass (such as windows). The remainder, $H_{t r, o p}$ is the transmission heat transfer coefficient for opaque elements (containing thermal mass), and it is divided into the external $\left(H_{t r, e m}\right)$ and the internal $\left(H_{t r, m s}\right)$ part. Both of them are connected to the single thermal capacity $\left(C_{m}\right.$, representing the zone thermal mass) which is located in between them. The internal air node $\left(\vartheta_{\text {air }}\right)$ and the internal surface node $\left(\vartheta_{s}\right)$ are connected through the coupling conductance $\left(H_{t r, i s}\right)$ defined between them. Heat flow rates obtained from internal $\left(\phi_{\text {int }}\right)$ and solar heat sources $\left(\phi_{s o l}\right)$ are divided into three parts. These are the following: $\phi_{i a}, \phi_{s t}$ and $\phi_{m}$ and they are connected to all of the above-mentioned nodes inside the external envelope of the building.

\subsubsection{Calculation of transmission heat transfer coefficients}

$H_{t r, e m}$ and $H_{t r, w}$ are calculated from heat transfer coefficients and areas of building elements exposed to heat transfer via transmission. $H_{v e}$ is obtained from heat flows caused by different air flows (infiltration, mechanical ventilation). $H_{t r, i s}$ and $H_{t r, e m}$ are calculated according to Equations 7.9 and 7.10 from [2]. $H_{t r, e m}$ depends on the effective mass area $\left(A_{m}\right)$ which is shown in Table 1. Distribution of heat flows from internal and solar heat sources also depends on this parameter.

Table 1 Default values of dynamic parameters

\begin{tabular}{|c|c|c|c|c|c|}
\hline Class & Very light & light & Medium & Heavy & Very heavy \\
\hline$A_{m}\left(\mathrm{~m}^{2}\right)$ & $2,5 \cdot A f$ & $2,5 \cdot A f$ & $2,5 \cdot A f$ & $3,0 \cdot A f$ & $3,0 \cdot A f$ \\
\hline
\end{tabular}




\subsubsection{Calculation procedure}

For each hour the actual internal temperature $\left(\vartheta_{\text {air }}\right)$ and the actual heating or cooling need $\left(\phi_{H C, n d}\right)$ are calculated using the stepwise procedure. The full set of equations and calculation procedure is given in [11], following Annex $\mathrm{C}$ in [2]. The procedure is iterative and consists of 4 steps. In the first step, it is checked if there is any need for cooling or heating. In the second, $\vartheta_{\text {air }}$ is calculated with $\phi_{H C \text {,nd }}$ defined in [2]. According to the linear interpolation between $\vartheta_{\text {air }}$ obtained for free floating conditions and that obtained with defined $\phi_{H C, n d}$, required $\phi_{H C, n d}$ is determined. In third step, the availability of required $\phi_{H C, n d}$ is checked. In the fourth step, $\vartheta_{\text {air }}$ is calculated with defined $\phi_{H C, n d}$ in step 3.

After that, the daily need for heating or cooling is calculated as follows:

$$
Q_{H C, n d, \text { day }}=\frac{1}{1000} \cdot \sum_{i=1}^{24} \phi_{H C, n d, i} \cdot t[\mathrm{kWh}]
$$

The difference in calculation methods is that in EC the simple hourly method from [2] is not applied as a hour-by-hour calculation procedure (in which the calculation starts from the first hour of the year and extents to the last hour of the year, with a time step of 1 hour), but operates with avg. day. Discussion on that is given below. Monthly need for heating or cooling is then calculated by multiplying the daily need for heating or cooling by number of heating or cooling days (taking into account weekly number of days of use as well), and yearly need for heating or cooling is obtained by summing monthly needs.

Heat transmission towards the ground is in [11] calculated according to [13] (Annex A), but not included in the overall heat transmission coefficient as in [2]. Monthly heat flow towards the ground $\left(\phi_{m}\right)$ is simplified in [11] and calculated using monthly average temperatures, as follows:

$$
\phi_{\mathrm{m}}=\mathrm{H}_{\mathrm{g}}\left(\overline{\vartheta_{\mathrm{lnt}}}-\overline{\vartheta_{\mathrm{e}}}\right)-\mathrm{H}_{\mathrm{pi}}\left(\overline{\vartheta_{\mathrm{lnt}}}-\vartheta_{\mathrm{int}, \mathrm{m}}\right)+\mathrm{H}_{\mathrm{pe}}\left(\overline{\vartheta_{\mathrm{e}}}-\vartheta_{\mathrm{e}, \mathrm{m}}\right)[\mathrm{W}]
$$

$H_{g}, H_{p i}$, and $H_{p e}$ are calculated according to equations (A.10), (F.4) and (F.5) in [13]. Indoor periodicity can usually be neglected if constant average internal temperature is assumed. External periodicity is calculated according to (F.5) in [13]. No sinusoidal temperature variations due to time lag are considered.

In IDA ICE heat transfer towards the ground is also calculated according to [13], but it adopts Annex D, which provides the model of heat transfer towards the ground calculations for dynamic simulation software [15], [16]. In this model, a $0.5 \mathrm{~m}$ layer of soil with given properties is placed below the ground floor of the building and a $0.1 \mathrm{~m}$ virtual layer is placed beneath it. The virtual layer is included so that boundary conditions for heat balance conditions can be set up and that the annual average heat flow is more precise. It is calculated with thermal resistance, computed according to (D.1) from [13], and a negligible thermal capacity. Heat transfer through layers is computed using finite difference method (hereafter, FDM) as it is the case with transmission through other opaque envelope elements. Temperature of the virtual layer is calculated as follows:

$$
\vartheta_{v, m}=\vartheta_{i n t, m}-\frac{\phi_{m}}{H_{g}}\left[{ }^{\circ} \mathrm{C}\right]
$$

If the time lag due to large accumulative capacity of ground is taken into account, then the monthly heat flow rate is calculated according to Equation (4):

$$
\phi_{m}=H_{g}\left(\overline{\vartheta_{\text {เnt }}}-\overline{\vartheta_{e}}\right)-H_{p i} \widehat{\vartheta_{\imath n t}} \cos \left(2 \pi-\frac{m-\tau+\alpha}{12}\right)+H_{p e} \widehat{\vartheta_{e}} \cos \left(2 \pi-\frac{m-\tau-\beta}{12}\right)
$$

In observed cases, internal periodicity is neglected. This is valid if internal temperature is kept at desired set-point. IDA ICE uses Equation (2) for calculation of the temperature of 
Differences in Calculations of Annual Heating and Cooling Energy Need Carried out by Modified Simple Hourly Method and Dynamic Simulations
N. Vujnović, D. Vidak, F. Jakšić, Ž. Kedmenec, D. Dović, I. Horvat

virtual layer, $\vartheta_{v}$, and combines it with Equation (3) to compute the monthly heat flow (needed to compute $\vartheta_{v}$ ), but shifts the mean monthly temperature of external air by value of $\beta$ (obtained from Table F.2 in [13], in months, for well-insulated slab on ground) and computes heat transfer through ground using FDM. In this way, the calculation is done with the time shift taken into account, resulting in reduced annual energy need for heating and greater annual energy need for cooling.

\subsubsection{Calculation of the distribution of heat flows from internal and solar heat gains}

5R1C model groups all the solar gains together (solar heat gains through opaque elements and solar heat gains through windows). This sum, in combination with internal heat gains, is then divided on three surface nodes that represent internal air temperature, zone surface temperature and effective mass temperature according to following equations (based on the effective mass area $\left(A_{m}\right)$ which is shown in Table 1.):

$$
\begin{aligned}
\phi_{\text {ia }} & =0.5 \phi_{\text {int }}[\mathrm{W}] \\
\phi_{m} & =\frac{A_{m}}{A_{\text {tot }}} \cdot\left(0.5 \phi_{\text {int }}+\phi_{\text {sol }}\right)[\mathrm{W}] \\
\phi_{s t} & =\left(1-\frac{A_{m}}{A_{\text {tot }}}-\frac{H_{t r, w}}{9.1 \cdot A_{t o t}}\right) \cdot\left(0.5 \phi_{\text {int }}+\phi_{\text {sol }}\right)[\mathrm{W}]
\end{aligned}
$$

This potentially means that this procedure results are in accordance with real building behaviour only in particular cases (certain categories of the building envelope and certain climatic conditions).This estimation leads to differences in results in energy need for heating and cooling compared to results of calculations performed by more precise dynamic simulation software. In IDA ICE, user can choose how to split internal gains (by giving a fraction of gains being treated as long-wave radiation heat source and the rest is being treated as a convective heat gain). Solar heat gains towards opaque elements of the envelope contribute to increase in internal nodes in wall layers and solar heat gains through transparent elements of the envelope contribute to increase in internal surfaces temperatures which then transfer heat to internal air by convection.

\subsubsection{Average day of the characteristic month vs. hour-by-hour calculation}

As mentioned before, EC operates with avg. day. In each month, avg. day is derived by averaging the climate data from test reference year (hereafter, TRY) for the given location (e.g. external air temperature, relative humidity of the air, insolation on surfaces considering their orientation and slope etc.) for each hour in the given month. This means that climate data for given hour of the avg. day is the mean value of given hour of all days in the observed month. The procedure is then following: the calculation is done for each hour of avg. day (with data from last hour of previous month's avg. day being the input data for the first step of calculation in the present month) and is repeated until reaching desired level of accuracy (with calculation data obtained from last hour of the present month's avg. day being the input data for the first hour). Number of heating or cooling days in month is calculated according to Equations (1.87) and (2.22) in [11]. Monthly energy need for cooling or heating is then obtained by multiplying energy need for heating or cooling in avg. day by number of heating or cooling days in month.

In IDA ICE a method for imitation of the above-described procedure was developed. For each month, a periodic simulation is done for the $15^{\text {th }}$ day of the month (in order to respect the average incident angle of the sun radiation, which is dependent on day of the year) and repeated 15 times to reach the sufficient accuracy level. Initial conditions are obtained by 
performing a dynamic start-up (dynamic hour-by-hour calculations of the period of 20 days before the $15^{\text {th }}$ day in the present month, data from the last hour of start-up is the input data for the first hour of calculation period). Climate data for the above-mentioned avg. day is obtained from EC for locations Zagreb (continental climate) and Split (maritime climate). Results are then multiplied by number of heating/cooling days acquired from EC to be comparable to it.

Also, a numerical hour-by-hour simulation was performed by IDA ICE. A year of 8760 hours with the data input from TRY file for the given location was simulated. Initial conditions are also set up by performing a dynamic start-up (dynamic calculations of the period of last 20 days of the year with the last hour being the input for the first hour of simulation period).

\subsection{Heat transfer through walls in IDA ICE}

In IDA ICE FDM is used for solving partial differential equations (hereafter, PDM) for heat transfer between cells in walls. The approach of FDM is to approximate the PDEs by discretizing the spatial dimension to convert the PDEs into ordinary differential equations (hereafter, ODEs) in time. ODEs are then solved by ODE solvers. Walls are divided into cells by layers (thicker layers are divided into more cells to calculate the temperature drop in the layer more precisely - every cell is characterised with thermal properties of the matching layer). The number of layers is user-defined. In every layer there is a node representing the thermal mass of the layer and every node is connected to a thermal resistance and capacitance. Due to greater number of nodes in building's envelope compared to calculations according to simple hourly method, heat accumulation in walls is more precisely described compared to the calculations performed with non-discretised wall layers [15].

Table 2 Differences between mentioned calculation methods

\begin{tabular}{|c|c|c|c|c|}
\hline Method/Parameter & Time step & $\begin{array}{l}\text { Nodes } \\
\text { representing } \\
\text { thermal mass }\end{array}$ & $\begin{array}{l}\text { Heat transfer } \\
\text { towards ground }\end{array}$ & $\begin{array}{l}\text { Distribution of } \\
\text { heat gains }\end{array}$ \\
\hline Simple hourly & 1 hour & 1 & $\begin{array}{l}H_{g} \text { included in } \\
\text { total } H_{t r} \text { (no time } \\
\text { shift) }\end{array}$ & Based on $A_{m}$ \\
\hline Simple hourly EC & $\begin{array}{l}1 \text { hour of } \\
\text { avg. day }\end{array}$ & 1 & $\begin{array}{c}\phi_{m} \text { calculated (no } \\
\text { time shift) }\end{array}$ & Based on $A_{m}$ \\
\hline$I D A I C E$ & 1 hour & $\begin{array}{l}\text { User-defined } \\
\text { number }\end{array}$ & \begin{tabular}{|c|}
$\phi_{\mathrm{m}}$ towards \\
virtual layer \\
calculated (with \\
time shift) \\
\end{tabular} & $\begin{array}{l}\text { Share of radiative } \\
\text { internal gains can be } \\
\text { user defined, solar } \\
\text { treated as heat source }\end{array}$ \\
\hline
\end{tabular}

\subsection{Building model}

A simple nearly zero-energy building (hereafter, nZEB) model was created. The building consists of two zones, each on its own level. Lower zone is connected to the ground via the ground floor and upper zone is separated from the lower with an internal slab (no heat flow towards the ground in the upper zone). Temperature set-points in both zones are identical so heat flow between zones is avoided. Inner dimensions of the floor are $8 \mathrm{~m} \times 8 \mathrm{~m}$ (conditioned zone area $64 \mathrm{~m}^{2}$ ) and the height of a zone is $2 \mathrm{~m}$ (volume of the zone $128 \mathrm{~m}^{3}$ ). External walls are well-insulated. Slab towards ground is insulated on perimeter to avoid thermal bridges on external wall/floor joint. Thermal properties of the building elements are shown in Table 3. 
Differences in Calculations of Annual Heating and Cooling Energy Need Carried out by Modified Simple Hourly Method and Dynamic Simulations
N. Vujnović, D. Vidak, F. Jakšić, Ž. Kedmenec, D. Dović, I. Horvat

Table 3 Thermal properties of building elements

\begin{tabular}{|c|c|c|c|}
\hline Building element & Thickness $[\mathrm{cm}]$ & Solar heat gain coefficient $[-]$ & U-value $\left[\mathrm{W} /\left(\mathrm{m}^{2} \mathrm{~K}\right)\right]$ \\
\hline External wall & 43.5 & - & 0.1878 \\
\hline Roof & 29.82 & - & 0.1314 \\
\hline Ground floor & 21.22 & - & 0.304 \\
\hline Window (if present) & - & 0.6 & 1.1 \\
\hline
\end{tabular}

If present in the simulation case, window is placed on the southern side of the building. Its area is $9 \mathrm{~m}^{2}$ (large enough so solar heat gains are significant). Building design is shown in Figure 2.
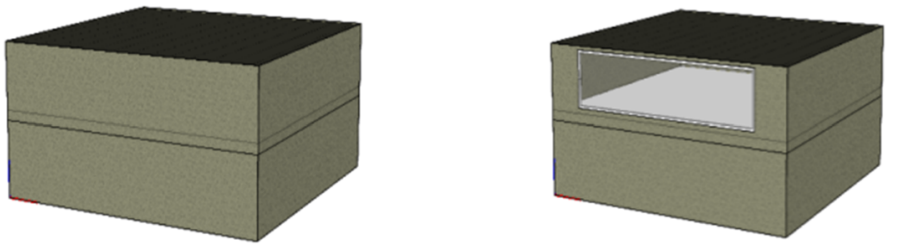

Fig. 2 Design of examined building

\subsection{Calculation settings}

Assumed occupancy is 24/7 with no technical systems being defined in EC. Energy need for heating and cooling is independent on the type of technical system because there is no building-system thermal interaction taken into account (this is valid only for calculation of energy need). To simulate those conditions, in IDA ICE ideal heater for heating and ideal cooler for cooling mathematical models were chosen. Ideal room units should be used to condition the zone when calculating the energy need without building-system thermal interaction. [15].

In the basic model the upper zone is being observed. There is no heat transfer other than by transmission through walls and by ventilation (fixed infiltration $\mathrm{ACH}$ rate $-0.52 \mathrm{~h}^{-1}$ ). In this case, heat transfer towards ground is also avoided. There are no internal or solar heat gains (both through opaque and transparent parts of the envelope). Heating set-point is $20^{\circ} \mathrm{C}$ and cooling set-point is $20.1{ }^{\circ} \mathrm{C}$ (the difference is set to $0.1{ }^{\circ} \mathrm{C}$ to make it easier to compare heat losses dependent on difference between indoor and external temperature). Calculations are conducted both for continental and maritime climate in Croatia.

In the next cases, one by one calculation settings were changed and the impacts of those changes on the final results in annual energy need for heating and cooling were examined and results obtained by different calculation methods were compared. After each change, calculation settings were reset to initial state. Firstly, internal gains were introduced, in IDA ICE both in 100\% convective and 50\% long-wave radiation, 50\% convective form. After that, annual energy need for heating and cooling was examined for more realistic set-points $\left(20^{\circ} \mathrm{C}\right.$ heating, and $22^{\circ} \mathrm{C}$ cooling for continental and $24^{\circ} \mathrm{C}$ cooling for maritime climate, according to [17]). In the next case, solar gains were introduced (through opaque and then trough transparent elements of envelope). Lower zone was also examined to determine the differences in heat transfer towards ground in previously described. Lastly, combined impact of all analysed changes on annual energy need for heating and cooling was examined. 


\section{Results}

In order to make results discussion more convenient, nomenclature for different simulation cases was introduced. It is shown in Table 4.

Table 4 Nomenclature of simulation cases

\begin{tabular}{|c|c|c|c|}
\hline Change in calculation settings & Code & Change in calculation settings & Code \\
\hline No change (basic model) & BAS & Solar gains (opaque elements) & SG-OP \\
\hline Internal gains & IG & Solar gains (transparent elements) & SG-TR \\
\hline Internal gains (50\% radiative) & IG-50 & Heat flow towards ground & GROUND \\
\hline Original set-points & SET & All changes introduced & ALL \\
\hline
\end{tabular}

Annual energy need for heating and cooling will be presented in the next two figures for both continental and maritime climate for Croatia.

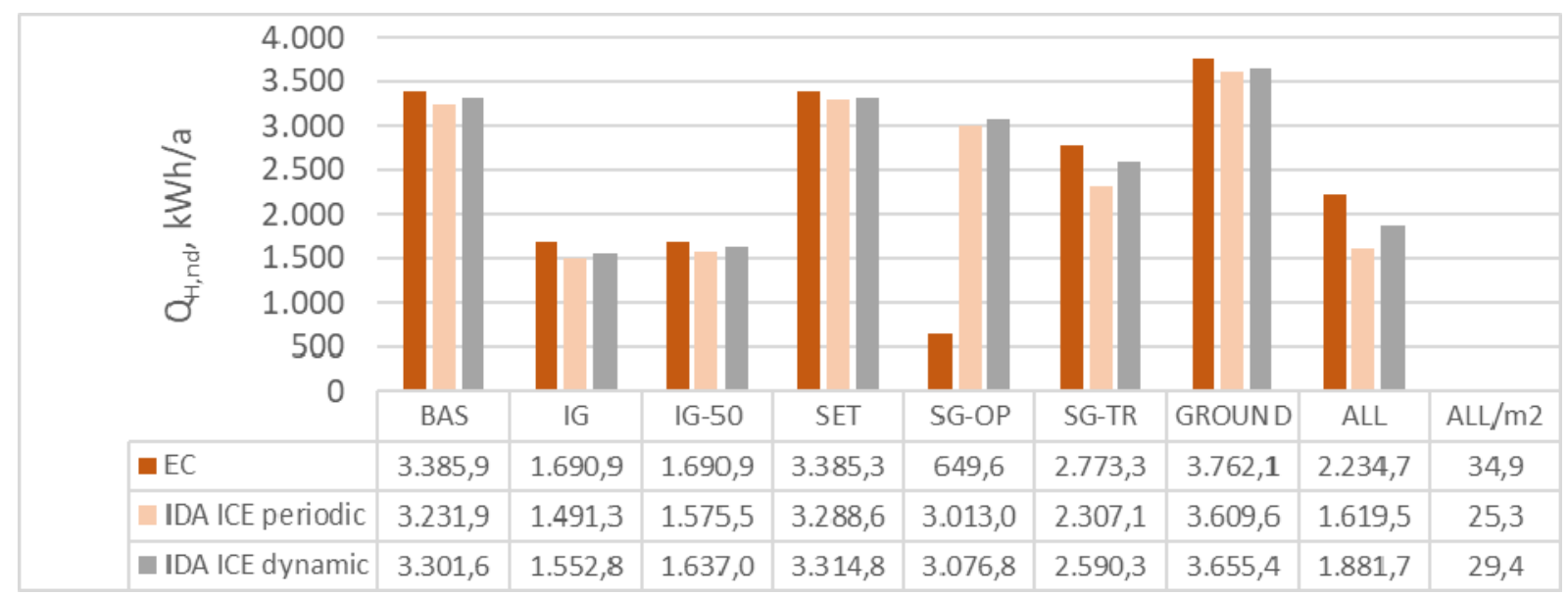

Fig. 3 Annual energy need for heating - continental Croatia

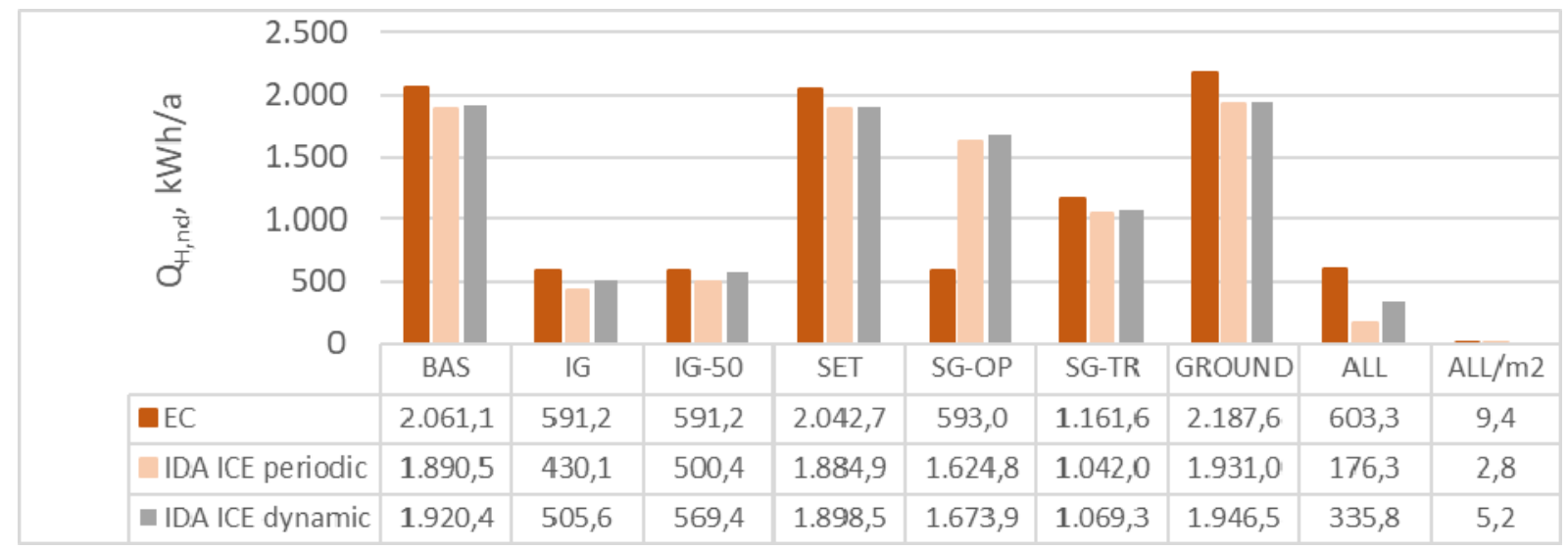

Fig. 4 Annual energy need for heating - maritime Croatia

In Figure 3 and Figure 4 it is noticeable that the pattern of change of annual energy need for heating $\left(Q_{H, n d}\right)$ in the results obtained from different calculation methods is the same for both continental and maritime climate for Croatia. $Q_{H, n d}$ is higher in calculations performed by EC than in those performed by IDA ICE. It can be assumed that this is a result of more detailed model of transient heat balance equations of external walls (increased number of nodes). Also, IDA ICE does not use as many simplifications as simple hourly method (all 
Differences in Calculations of Annual Heating and Cooling Energy Need Carried out by Modified Simple Hourly Method and Dynamic Simulations
N. Vujnović, D. Vidak, F. Jakšić, Ž. Kedmenec, D. Dović, I. Horvat

described in previous sections). Hour-by-hour dynamic calculations also result in slightly increased $Q_{H, n d}$ when compared to periodic simulations in IDA. The reason for this is simple, in "transitional" months due to the averaged climatic data the extremes have "disappeared", i.e. in months that are not treated as months with exclusive heating or cooling need (such as March, April, September, October) there are some days when climate data odd from the average day of the month, which results in an increased need for heating on the monthly level compared to avg. day. Since energy need for heating is a sum (an integral) of the hourly need for heating throughout the whole year when performing hour-by-hour simulations, those hours or days are integrated in the annual energy need, thus increasing it. The difference is also in initial conditions when observing each day, in EC they are the same for each day of the month (last hour of characteristic day) and in IDA ICE they differ every day of the year (last hour of the previous day). Energy need for heating in SG-OP case is unfortunately not comparable between EC and IDA ICE, because in EC number of heating days equals 0 due to its inability to calculate heating days when monthly external heat gains are negative (which occurs in winter months when more energy is emitted towards the sky than gained through solar radiation). Here should also be noted that this is not a realistic case.

In the next two figures, annual energy need for cooling is presented.

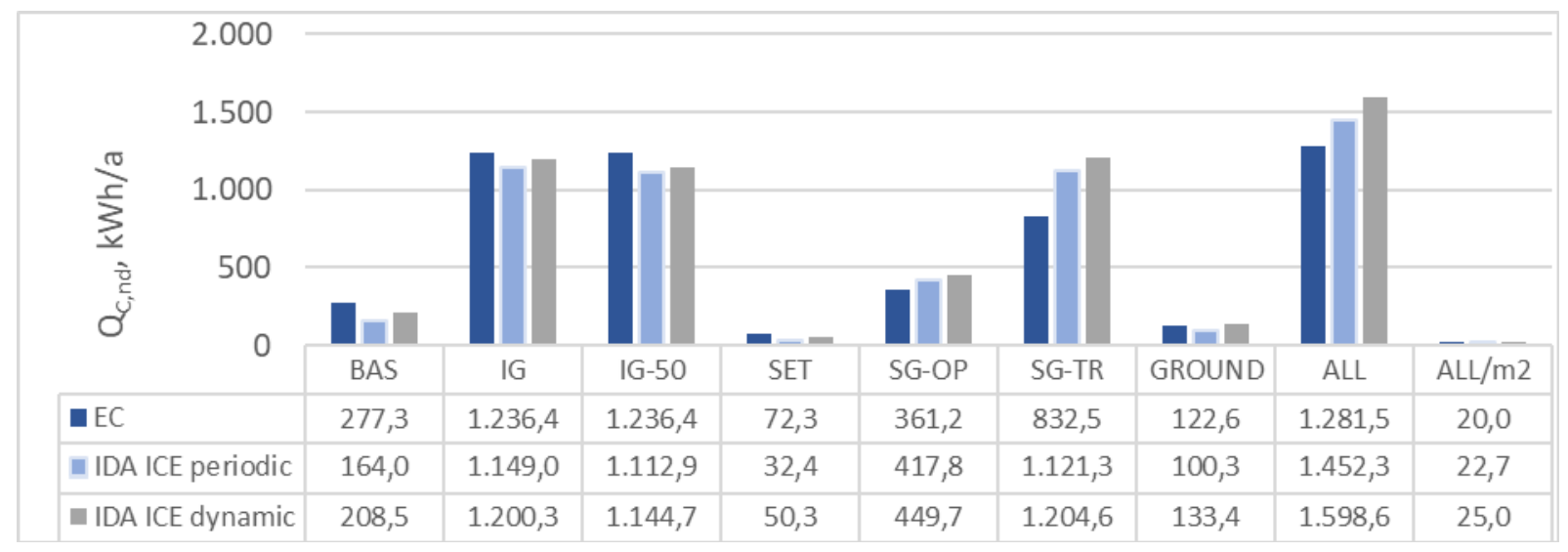

Fig. 5 Annual energy need for cooling - continental Croatia

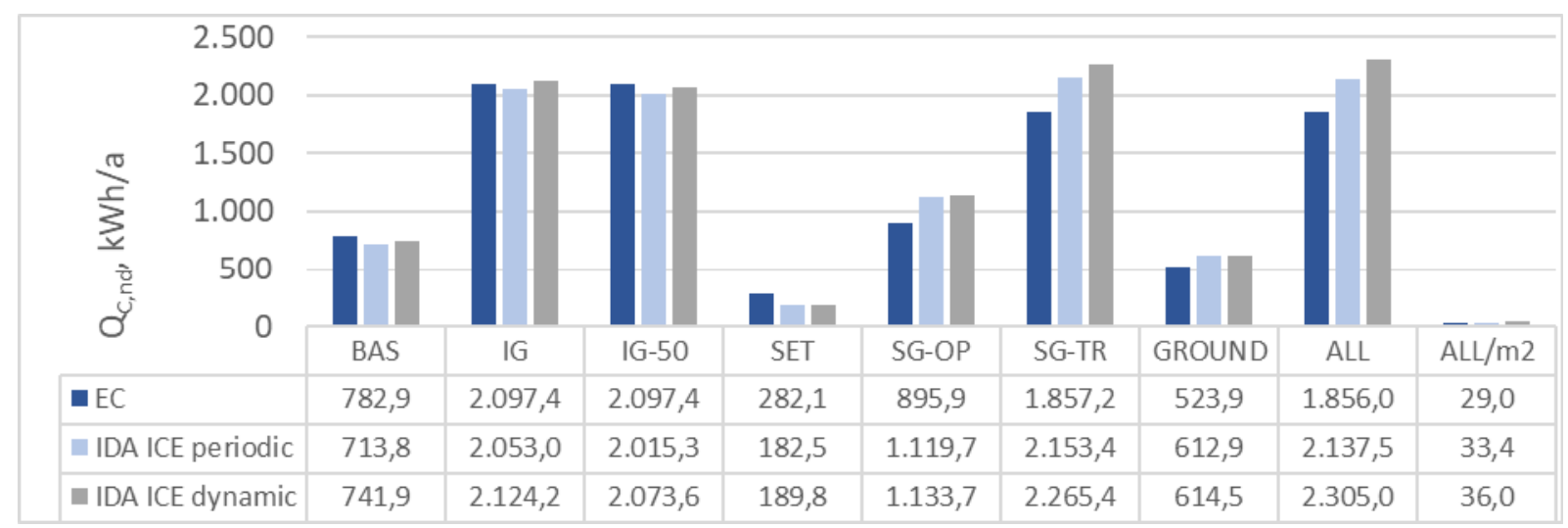

Fig. 6 Annual energy need for cooling - maritime Croatia

When studying annual energy need for cooling $\left(Q_{C, n d}\right)$ in different simulation cases for both continental and maritime climate, it is easily concluded that the similar pattern of change of results to that of $Q_{H, n d}$ exists. The reason is the same - days in months that have not exclusive heating or cooling demand. The difference can be seen in SG-TR and SG-OP cases, 
where the difference is caused by the treatment of solar heat gains, and also in cases when heat transmission through the ground floor is considered (due to the time shift, the floor does not cool the space the same in IDA ICE and EC).

Mentioned difference in $Q_{H, n d}$ and $Q_{C, n d}$ between exclusively heating/cooling months and "transitional" months is shown in the following charts. Sum of $Q_{H, n d}$ in May and September vs. that in January and December is given for continental climate (BAS). Sum of $Q_{C, n d}$ in April and October vs. that in July and August is given for maritime climate (SOL-TR). In those cases the differences are most noticeable.

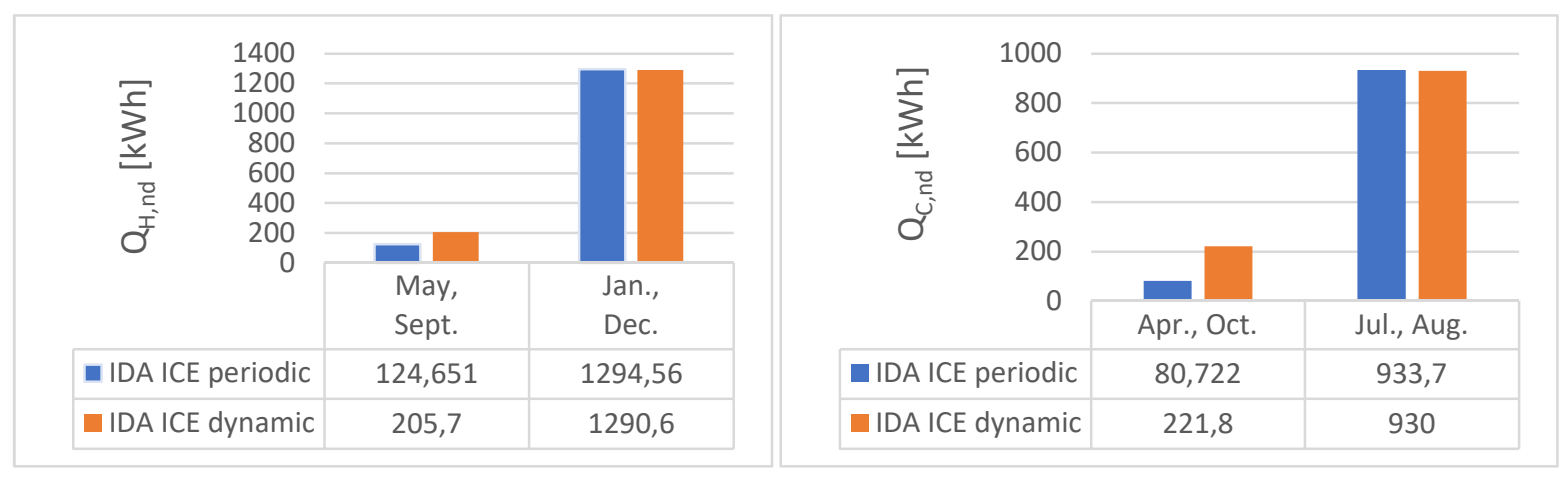

Fig. 7 Comparison of $\mathrm{Q}_{\mathrm{H}, \mathrm{nd}}$ and $\mathrm{Q}_{\mathrm{C}, \text { nd }}$ for "transitional” and heating/cooling months

\subsection{Discussion on results for each change in calculation settings}

BAS. In the basic model, the only difference is, as said before, the more detailed description of heat transfer through walls in IDA ICE. The small difference in $Q_{H, \text { nd }}$ and more visible difference $Q_{C, n d}$ stem from that.

IG and IG-50. By adding internal gains, $Q_{H, n d}$ has decreased by a bit greater amount (5\% more) in IDA ICE compared to EC. $Q_{C, n d}$ has increased by a bit greater amount in IDA ICE compared to EC, which means that the difference in treatment of internal gains contributes in a small amount to differences in results. The distinction in IDA ICE cases when $50 \%$ of internal gains in dynamic simulations are treated as radiative heat source is visible, resulting in $5.5 \%$ greater $Q_{H, n d}$ and $2 \%$ lower $Q_{C, n d}$.

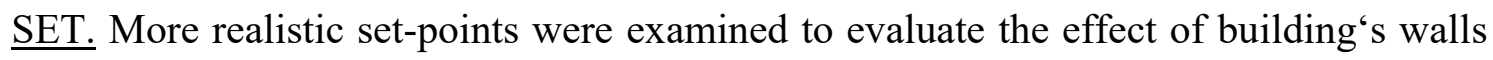
heat accumulation due to different indoor temperatures (because of delayed start of cooling). The differences are negligible (when discussing $Q_{H, n d}$ ).

SG-OP Due to above-mentioned problems in determining number of heating days when total heat gains are negative, $Q_{H, n d}$ obtained by EC is not comparable to that obtained by IDA ICE. However, $Q_{C, n d}$ is comparable and shows the difference in treatment of solar heat gains through opaque elements of envelope. Their accumulation in walls of the building is better described in IDA ICE, which results in increased annual need for cooling $(25 \%$ higher in maritime climate). Dynamic simulation in IDA ICE will result in increased $Q_{C, n d}$ compared to periodic simulation in IDA ICE due to mentioned differences in "transitional" months and the facts that heat accumulation hour-by-hour is more realistic than that in avg. day (because of mentioned difference in initial conditions of every day). Also, the change in climate data in the beginning of the month is smooth, not a steep change as in EC (using characteristic day).

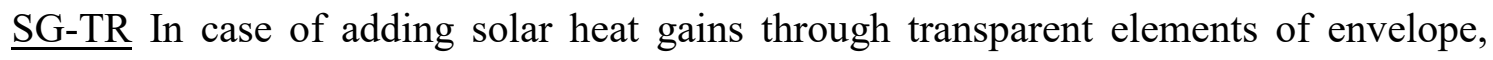
$Q_{H, n d}$ can be compared between EC and IDA ICE periodic and dynamic simulations too. Solar 
heat gains and their accumulation in the building walls, as said before, seem to be underestimated by [11], which can be observed both in decreased $Q_{H, n d}$ in IDA ICE compared to EC and increased $Q_{C, n d}$. Both $Q_{H, n d}$ and $Q_{C, n d}$ are higher in IDA ICE dynamic than in periodic simulation due to previously named causes. The conclusion is that an average day of a characteristic month is not an appropriate way of reducing the needed amount of calculations for annual energy need for cooling and heating. Such an approach does not cover temperature and solar radiation peaks. Perhaps a more appropriate way for reducing the needed amount of calculations is the use of the mode day - the day that has appeared for the most times in the month.

GROUND. Temperature of external air is shifted in IDA ICE by two months when calculating temperature of virtual layer so the greatest heat losses in heating season towards ground do not take place in months with lowest external air temperatures and the greatest losses in cooling season do not take place in months with highest external air temperatures, as it is case in EC. This way, heat flow towards the ground does not cause increased demand for heating in winter months and decreased need for cooling in summer months. That results in a bit lower $Q_{H, n d}$ and higher $Q_{C, n d}$ in IDA ICE compared to EC. In both cases, yearly heat flow towards the ground is approximately a sinusoid, but with a phase difference of 2 months. Monthly heat flow towards the ground is shown in Figure 8. Positive value represents heat loss for the zone.

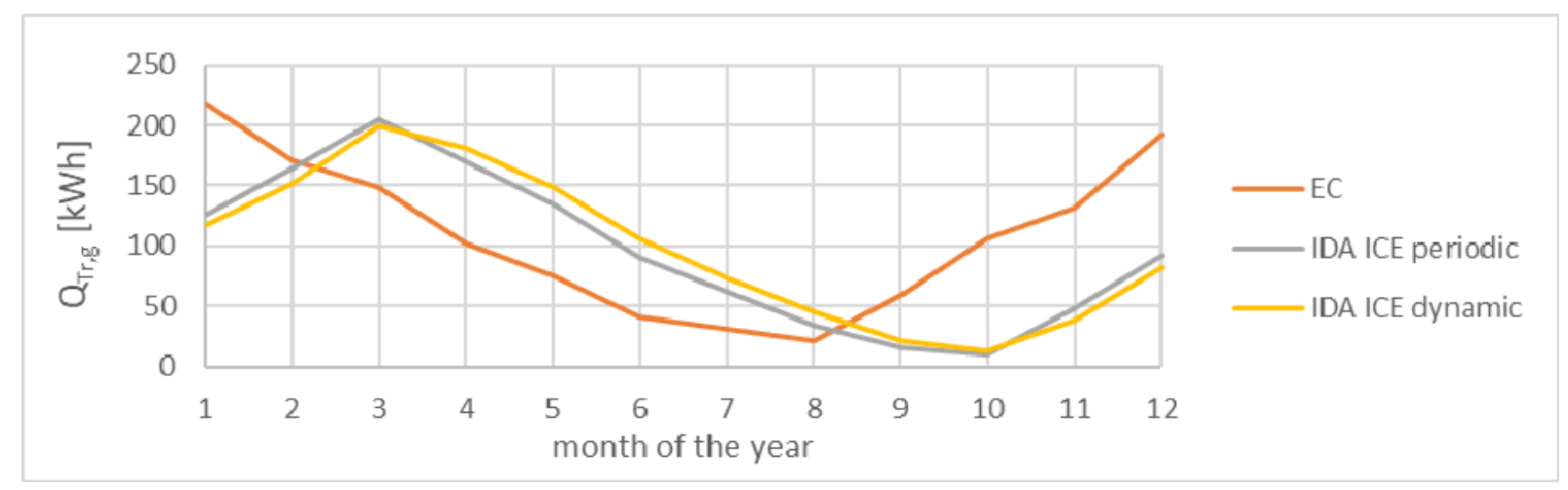

Fig. 8 Monthly heat transfer through the ground floor

ALL. When analysing results with all the mentioned changes introduced, it can be concluded that the main impact on differences in results obtained by different calculation procedures is that of model of accumulation of solar heat gains, particularly through transparent parts (due to both mathematical model of building wall and introduced simplification of simple hourly method). Second influence is heat flow towards the ground. All this results in decreased $Q_{H, n d}$ (which is comparable to other cases due to same heating set-point) and increased $Q_{C, n d}$ in IDA ICE compared to EC (not comparable to all other cases due to different set-points). $Q_{H, n d}$ is lower in IDA ICE than in EC approximately by the sum of differences in $Q_{H, n d}$ between IDA ICE and EC in IG, SG-TR and GROUND.

\section{Conclusion}

A comparison between annual energy need for heating and cooling obtained by calculation procedure from [2] (as implemented in EC software) and numerical dynamic simulations performed by IDA ICE software is presented. The simple hourly method from [2] and its implementation into [11] is described, as well as differences between simple hourly 
method and numerical dynamic simulations. Impact of different changes in boundary and initial conditions on results obtained by observed version of simple hourly method and numerical dynamic simulations is examined. Results (annual energy need for heating and cooling) for each of those cases are shown and analysed.

Accumulation of solar heat gains in walls of the building is marked as the main cause of differences in results in different cases. When solar heat gains through transparent parts of the envelope are considered, $Q_{C, n d}$ for maritime climate obtained by EC is $13.8 \%$ lower relative to the calculation for average day of the characteristic month in IDA ICE. Also, hour-by-hour simulation results in $5.2 \%$ higher $Q_{C, n d}$ compared to periodic simulation. Distinction in splitting solar and internal and heat gains contributes to these differences as well.

Difference in heat transfer towards the ground is also significant because monthly heat flow rate is shifted by two months in IDA ICE due to heat accumulation in ground, (in EC this is not the case). This results in $13.2 \%$ higher $Q_{H, n d}$ obtained by EC compared to periodic calculations in IDA ICE and $14.5 \%$ lower $Q_{C, n d}$ obtained by EC compared with periodic calculations in IDA ICE for maritime climate.

When all the changes are introduced in the simulation model, the result is $38 \%$ higher $Q_{H, n d}$ obtained by EC compared to IDA ICE periodic simulation and $16.2 \%$ higher $Q_{H, n d}$ obtained by IDA ICE dynamic simulation for continental climate compared to IDA ICE periodic simulation. $Q_{C, n d}$ obtained by EC is $11.2 \%$ lower than that obtained by IDA ICE periodic simulation. $Q_{C, n d}$ obtained by IDA ICE dynamic simulation is $10 \%$ higher than that obtained by IDA ICE periodic simulation. This is the result of combination of the abovementioned factors.

General observation is the difference in $Q_{C, n d}$ and $Q_{H, n d}$ obtained by EC and IDA ICE periodic simulations performed with average day of characteristic month. The main cause is the distinction in the model of accumulation of solar heat gains. The next observation are higher $Q_{C, n d}$ and $Q_{H, n d}$ obtained by IDA ICE dynamic simulations compared to those obtained by IDA ICE periodic simulations. The reason for this is inability of the method of avg. day to reflect properly climate data (air temperature, solar radiation) in "transitional" months. Results in the months that are exclusively heating or cooling months do match. In order to get more accurate results and to reduce the number of calculations (time steps), some other method than averaging the day of characteristic month should be implemented. As a potential solution, performance of calculations with the mode day (the day that has appeared the most times in the characteristic month) imposes.

\section{NOMENCLATURE}

$A_{f} \quad$ ground floor surface area $\left[\mathrm{m}^{2}\right]$

$Q_{H C, n d}$ energy need for heating or cooling in one day [kWh]

$\phi_{i a} \quad \phi$ heat flow rate from internal and solar gains towards the air node [W]

$\phi_{m} \quad$ heat flow rate from internal and solar gains towards the thermal mass node [W]

$\phi_{s t} \quad$ heat flow rate from internal and solar gains towards the surface node [W]

$t \quad$ time step of 1 hour

$H_{g} \quad$ steady-state transmission heat transfer coefficient towards ground [W/K]

$H_{p i} \quad$ internal periodic transmission heat transfer coefficient towards ground [W/K]

$H_{p e} \quad$ external periodic transmission heat transfer coefficient towards ground [W/K] 
Differences in Calculations of Annual Heating and Cooling Energy Need Carried out by Modified Simple Hourly Method and Dynamic Simulations
N. Vujnović, D. Vidak, F. Jakšić, Ž. Kedmenec, D. Dović, I. Horvat

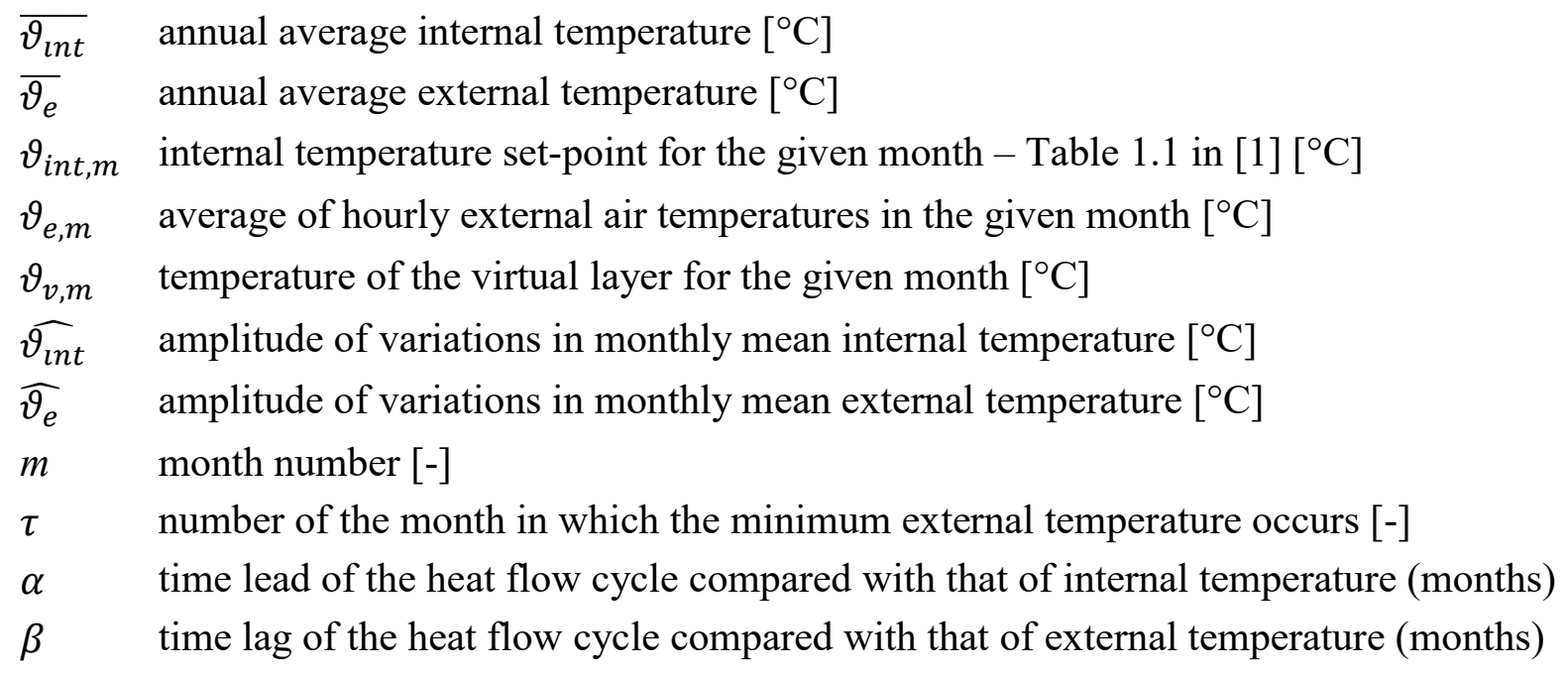

\section{REFERENCES}

[1] EPBD recast: Directive 2010/31/EU of the European Parliament and of Council of 19 May 2010 on the energy performance of buildings (recast), EU directive, Official Journal of the European Union, Bruxelles, 2010.

[2] HRN EN ISO 13790:2008 Energy performance of buildings - Calculation of energy use for space heating and cooling, National standard, Croatian Standards Institute, Zagreb, 2008.

[3] Michalak P., The simple hourly method of EN ISO 13790 standard in Matlab/Simulink: a comparative study for the climatic conditions of Poland, Energy, 75:568-78, 2014. https://doi.org/10.1016/j.energy.2014.08.019

[4] Mendes N., Oliveira G.H.C., de Araúj H.X., Building thermal performance analysis using Matlab/Simulink, In: Seventh international IBPSA conference, 2001.

[5] Qin M.H., Walton G., Belarbi R., Allard F., Simulation of whole building coupled hygrothermal-airflow transfer in different climates, Energy Convers Manage 2011;52(2):1470-8. https://doi.org/10.1016/j.enconman.2010.10.010

[6] De Rosa M., Bianco V., Scarpa F., Tagliafico L.A. Heating and cooling building energy demand evaluation: a simplified model and a modified degree days approach, Appl Energy 2014;128:217-29. https://doi.org/10.1016/j.apenergy.2014.04.067

[7] Lu S., Lu T., Kibert C.J., Viljanen M. A novel dynamic modelling approach for predicting building energy performance, Appl Energy 204;114:91-103. https://doi.org/10.1016/j.apenergy.2013.08.093

[8] Van der Veken, J., Saelens, D., Verbeeck, G., Hens, H. Comparison of Steady-State and Dynamic Building Energy Simulation Programs, Proceedings of the international Buildings IX ASHRAE conference on the performance of exterior envelopes of whole buildings, Clearwater Beach, Florida, 2004.

[9] Evangelisti, L., Battista, G., Guattari, C., Basilicata, C., Vollaro, R. d. L. Analysis of Two Models for Evaluating the Energy Performance of Different Buildings, Sustainability, vol. 6, pp. 5311-5321, 2014. https://doi.org/10.3390/su6085311

[10] Delač, B., Optimization of energy systems for nearly zero energy buildings using dynamic simulations, Doctoral thesis, University of Rijeka, Faculty of Engineering, Rijeka, 2017.

[11] Stapić, Z. et al.: Korisnička dokumentacija za rad u računalnom programu MGIPU Energetski certifikator, user manual, University of Zagreb, Faculty of Mechanical Engineering and Naval Architecture, Zagreb, 2017, https://mgipu.gov.hr/UserDocsImages/dokumenti/EnergetskaUcinkovitost/RacunalniProgram/Korisni\%C 4\%8Dka_dokumentacija_v1803.pdf

[12] Soldo, V., Novak, S., Horvat, I., Algorithm for calculation of the annual heating and cooling energy need according to EN ISO 13790, University of Zagreb, Faculty of Mechanical Engineering and Naval Architecture, Zagreb, 2017. Bilo 2

[13] HRN EN ISO 13370:2008 Thermal performance of buildings - Heat transfer via the ground - Calculation methods, National standard, Croatian Standards Institute, Zagreb, 2008. 
[14] Horvat, I., Dović, D., Dynamic method for calculating energy need in HVAC systems, Trans. of FAMENA, Vol. 40, No SI-1, 2016.

[15] User manual, IDA Indoor Climate and Energy, User manual, Equa Simulation AB, Solna, 2013.

[16] Bring, A., Sahlin, P., Vuolle, M.: Models for Building Indoor Climate and Energy, Task report, KTH Stockholm, 2000

[17] Ministry of Construction and Physical Planning of Croatia, Technical regulation on energy economy and heat retention in buildings, National Technical Regulation, Official Gazette 128/15, 70/18, 73/18, 86/18)

Submitted: $\quad 14.06 .2019$

Accepted: $\quad$ 11.7.2020
Nikola Vujnović

Dean Vidak

Fran Jakšić

Željko Kedmenec

Ekonerg - Energy and Environmental

Protection Institute Ltd., Koranska 5, 10000 Zagreb, Croatia

Damir Dović

Ivan Horvat

Univesity of Zagreb, Faculty of

Mechanical Engineering and Naval

Architecture, Ivana Lučića 5, 10000

Zagreb, Croatia 